\title{
Uncertainty Analysis in Life Cycle Assessments Applied to Biorefineries Systems: A Critical Review of the Literature
}

\author{
Richardson Silva Lima ${ }^{1}$ (D) Armando de Azevedo Caldeira-Pires $^{2}$ (i) $\cdot$ Alexandre Nunes Cardoso $^{1}$
}

Received: 22 August 2019 / Revised: 12 November 2019 / Accepted: 26 December 2019 / Published online: 11 January 2020

(C) The Author(s) 2020

\begin{abstract}
The aim of the present article was to investigate the relationship between uncertainty analysis and life cycle assessment (LCA) in scientific publications that address the application of LCA in biorefineries systems. Uncertainty analysis and its relationship with environmental impact assessment studies, especially those that address the application of LCA, is a research topic that requires attention because of its possible influence on results. A reference base was defined using a systematic approach and bibliometric analysis, with 64 scientific publications extracted from the Web of Science (WoS) and Scopus $®$ databases, which were analyzed using two computational tools: VOSviewer and SciMAT. This group of publications helped establish the correlation and evolution over the last 10 years of the three key themes: "uncertainty analysis," "LCA," and "biorefineries." The results of bibliometric analysis for the established framework pointed to a close and important relationship among these themes. The results were presented quantitatively and qualitatively, and the latter were visualized using infographics, co-occurrence networks, and strategic keyword diagrams. Although the study confirmed the relevance of uncertainties analysis to support LCA studies, it was identified a secondary role for scientific studies analyzed. The study also presents the analysis and discussions of the main publications found in the scientific literature. Future studies should conduct a more in-depth analysis of advanced knowledge representation and reasoning strategies about uncertainty, such as probabilistic ontologies.
\end{abstract}

Keywords Uncertainty analysis $\cdot$ Life cycle assessment $($ LCA $) \cdot$ Biorefinery $\cdot$ VOSviewer $\cdot$ SciMAT $\cdot$ Probabilistic ontologies

\section{Introduction}

The environmental performance of products and services has become an important factor in the new economic context that has been emergent in recent years. This context is guided by the principles of bioeconomies and their relationships with circular economies. A bioeconomy is defined as an economy whose basic pillars of production, such as materials, chemicals, and energy products, are derived from renewable sources, providing alternatives to fossil fuel-based products and energy (European Commision 2015; Embrapa 2018). Circular economy is defined by Saavedra et al. (2018) as the study of real-life nonlinear systems to facilitate efficient flows

Richardson Silva Lima

richardson.lima@embrapa.br

1 Crosscutting Studies Group, Embrapa Agroenergy, Brasília, DF CEP 70770-901, Brazil

2 Center for Sustainable Development, University of Brasília (UnB), Brasília, DF CEP 70.904-970, Brazil of materials, energy, work, and information, promoting circular flows that reduce environmental impacts and optimize resource efficiency. In circular economies, the economic and environmental value of materials is preserved as long as possible, keeping them in the economic system, whether by increasing the lifetime of the products derived from them or returning them to the system for reuse (den Hollander et al. 2017; Saavedra et al. 2018). The relevance of these two concepts is that both offer approaches and challenges for handling environmental impacts, such as climate change, land and water use, and toxic emissions, which are the target of discussions in forums around the world, such as the United Nations Climate Change Conference and Europe's Bioeconomy Strategy.

Several tools can be used to measure these impacts: life cycle assessment (LCA), strategic environmental assessment (SEA), environmental impact assessment (EIA), environmental risk assessment (ERA), cost-benefit analysis (CBA), material flow analysis (MFA), and the ecological footprint (EF) method. The studies of Finnveden et al. (2009) and Stavropoulos et al. (2016) showed that LCA is one of the most 
well-known approaches. According to Finnveden et al. (2009) and Klöpffer (2014), interest in LCA grew quickly in the 1990 s, and during this period, two of the method's main features were presented: (1) comparison of production systems using a functional unit, e.g., a $1000 \mathrm{~L}$ container of a beverage and its transportation to the sales point, and (2) the possibility of cradle-to-grave analysis, including assessment of all the important phases of a product or service's life cycle. Life cycle assessment has been applied in several cases. Cherubini and Ulgiati (2010), presented a review of the assessment of potential environmental impacts of biomass-derived energy. You et al. (2012) determined greenhouse gas (Gg) balance, global carbon balance, and renewable energy returns in comparison with fossil fuel inputs. There have also been studies assessing the environmental impact of the production of bioproducts and renewable chemicals that can be obtained from biorefinery systems (Yue et al. 2014; Carneiro et al. 2017), among others.

The LCA technique identifies potential environmental impacts, and in this context, it does not predict absolute or precise impacts because, among other factors, of uncertainties inherent in data collection and modeling of these impacts (Klöpffer 2014). An adequate analysis of these uncertainties helps prioritize the choices made throughout the study of impact analysis using LCA. Identifying these uncertainties, as well as their sources and types, allows for increased data transparency and reliability of results, preventing unfeasible or misguided decisions (Baker and Lepech 2009; Curran 2012).

Sources of uncertainty have been defined in Finnveden et al. (2009) as input data for LCA methods that may be uncertain and directly related to several types of uncertainty. Uncertainty in LCA studies can stem from various sources, including low quality and/or absence of data, system limitations, and allocation principles; the time frame adopted for impact assessment; assumptions based on the wrong models; and phenomena in domains subject to statistical fluctuations (Curran 2012; Guo and Murphy 2012; Gargalo et al. 2016; Carvalho et al. 2016).

Types of uncertainty can be understood as aspects that can be wrong (unreliable) if derived from these sources (Finnveden et al. 2009). Some examples of types of uncertainty include choices inconsistent with the goal and scope of the impact assessment study; technological evolution; changes in incentives and government policy; different allocation methods for different supply chains; weather variations; supply of raw materials (feedstocks); and price and cost volatility (Frischknecht et al. 2005; Finnveden et al. 2009; Awudu and Zhang 2012; You et al. 2012; Yue et al. 2014; Mirkouei et al. 2017).

The main goal of the present study was to identify the extent to which uncertainty analysis is addressed in impact assessment studies using the LCA method applied to technological systems defined as biorefineries, through a systematic and bibliometric specialized literature review. In addition, the study indicates the most cited authors and publications, providing their main outputs. Table 1 presents the definitions adopted for the three key terms used in this study: uncertainty analysis, $L C A$, and biorefinery.

\section{Methodology}

The methodology used in this survey consisted of three phases. (1) systematic approach, (2) bibliometric analysis, and (3) discussion of the results of phase 2 (Cronin et al. 2008; Saavedra et al. 2018).

Phase 1 was further divided into three steps: (1) defining the conceptual problem, (2) adopting inclusion and exclusion criteria, and (3) data collection. In step 1, the terms life cycle assessment*, life cycle assessment*, life cycle analy*, life cycle analy*, life cycle assessment (LCA), LCA, uncertaint*; uncertaint* analy*; bioref*, and bio-ref* were established as the keywords to qualify the themes uncertainty analysis, $L C A$, and biorefineries. In steps 2 and 3, only publications written in English from two scientific literature databases were analyzed, the Web of Science (WoS) and Scopus $®$, starting from the first year available in the database up to the year of the study. Because the WoS does not allow for direct searches in its keyword field, which is different from the Scopus $₫$ database, the Boolean operators "or" and "and" were used in the search fields identified as "Topic" (WoS) and "Title-AbstractKeywords" (Scopus $®)$. These fields are equivalent.

Using these parameters, 55 publications were found in WoS and 33 in Scopus ${ }^{\circledR}$, being that the WoS included $72.7 \%$ of the results found in Scopus ${ }^{\circledR}$. For this reason, the WoS was chosen as the reference base for the computational data analysis tools. However, to ensure that the results of both databases were considered in the study, the remaining nine publications $(27.3 \%)$ were also included. Thus, the basis of reference consisted of 64 publications. The search was conducted in the third week of October 2018.

In Phase 2, bibliometric analysis was conducted to characterize, structure, and quantitatively analyze the field of research and the impact of a set of researchers, for a set of scientific journals or a given publication (Cobo et al. 2011; Gutiérrez-Salcedo et al. 2017; Marques et al. 2018). This approach has been used in bibliographic reviews in the very different fields of knowledge. van Leeuwen (2006) reviewed the evolution of social science research; Wagner et al. (2011) analyzed interdisciplinarity in scientific research; Burnard et al. (2017) examined environmental impact assessment with wood modification; Castillo-Vergara et al. (2018) investigated creativity in the context of economy; Saavedra et al. (2018) reviewed the literature on the contribution of industrial ecology to circular economy.

Different types of software have been used to carry out bibliometric analysis, including: Sci2 (Team 2009), SciMAT 
Table 1 Definitions of the three key terms used in this study

\begin{tabular}{|c|c|}
\hline Theme & Definition \\
\hline $\begin{array}{l}\text { Uncertainty } \\
\text { analysis }\end{array}$ & $\begin{array}{l}\text { ISO } 14044 \text { norms (requirements and guidelines for LCA) define uncertainty analysis as a } \\
\text { systematic procedure to quantify the uncertainty introduced in the results of a life cycle } \\
\text { inventory analysis due to the cumulative effects of model imprecision, input uncertainty, } \\
\text { and data variability (Baker and Lepech 2009; Curran 2012; Guo and Murphy 2012; Sills } \\
\text { et al. 2013; Klöpffer 2014; Hellweg and Mila i Canals 2014; Tang et al. 2015). In addition } \\
\text { to this definition, it is also important to consider the sensitivity analysis concept as an } \\
\text { approach to identify which input parameters carry out more or less influence on the final } \\
\text { results on LCA model (Baker and Lepech 2009) }\end{array}$ \\
\hline LCA & $\begin{array}{l}\text { A method that assesses the environmental impact of a given product or service throughout its } \\
\text { lifetime; its goal is to make the environmental performance of products and services } \\
\text { comparable, in addition to allowing consumers to choose the ones with the lowest burden. } \\
\text { Four phases are applied when using this technique, in conformity with ISO } 14040 \\
\text { (principles and structure) and 14044: definition of scope and objective, inventory (data } \\
\text { collection), impact assessment, and interpretation (Rebitzer et al. 2004; Guinée et al. } \\
\text { 2011; Curran 2012; Klöpffer 2014; Stavropoulos et al. 2016) }\end{array}$ \\
\hline Biorefineries & $\begin{array}{l}\text { Industrial plants that carry out sustainable conversion processes of biomass into products } \\
\text { (such as chemical materials and feedstock) and/or energy (electricity, fuel, and heat). } \\
\text { Biorefinery systems can mitigate the impacts of climate change, reduce dependence on } \\
\text { fossil fuels, and increase cleaner supply chains based on the sustainable processing of } \\
\text { biomass (Cherubini and Ulgiati 2010; Souza and Seabra 2014; Cong and Termansen } \\
\text { 2016; Rosengart et al. 2017; Mirkouei et al. 2017; Embrapa 2018; Ubando et al. 2019; } \\
\text { Venkata Mohan et al. 2019) }\end{array}$ \\
\hline
\end{tabular}

(Cobo et al. 2011, 2012), VOSviewer (Perianes-Rodriguez et al. 2016; Van Eck and Waltman 2018), VantagePoint® (Search Technology 1997), and CitNetExplorer (van Eck and Waltman 2014). The present study used VOSviewer (version 1.6.9) and SciMAT (version 1.1.04); both are opensource software and compatible with the WoS and Scopus ${ }^{\circledR}$ database formats. The VOSviewer is a tool for constructing and visualizing bibliometric networks, presenting correlations between the analyzed data (such as authors, keywords and journals), while SciMAT provides important characteristics that allow for data preprocessing, statistical analysis, graphic representation of results, and clustering algorithms for complete bibliometric analysis. A complete review of the features of these tools is presented by Gutiérrez-Salcedo et al. (2017).

The VOSviewer was set up as follows: (1) a thesaurus file with equivalent terms was created; (2) instead of full counting, a fractional counting algorithm was applied, based on the methodology presented by Perianes-Rodriguez et al. (2016); (3) a minimum number of keyword occurrences were set $\left(V_{\text {min. occurr }}\right)$, which indicates the number of publications in which the keyword appeared at least once, and $V_{\text {min. occurr. }}=5$ was defined to exclude terms with a low number of occurrences $\left(V_{\text {min. occurr. }}<5\right)$ and to avoid the indication of a low number of terms, restricting the analysis set $\left(V_{\text {min. occurr. }}>5\right)$; and (4) the identified terms were conceptualized as "main keywords."

The SciMAT program was set up in three steps: (1) selecting time periods for analysis, (2) eliminating false positives and negatives, and (3) defining calibration parameters for the bibliometric analysis algorithms. In Step 1, the analyzed time frame was split into two periods: 2008-2014 and 2015-2018.
This allowed for a good distribution of publications for scientific mapping analysis, with a total of 26 publications in 2008-2014 and 38 publications in 2015-2018. In Step 2 , search algorithms were used for plurals and distance, which were integrated into the tool, thus grouping similar keywords such as biofuel and biofuels, biorefinery and biorefineries, LCA and life-cycle assessment, and uncertainty and uncertainties. In this step, keywords that were not meaningful in the context of the study or were too broad in meaning were excluded, such as model, case study, design, challenges, perspective, methodology, technologies, management, and system. Next, in Step 3, the keyword was selected as the unit of analysis, and the other parameters were defined based on the methodologies presented by Cobo et al. (2011), Cavalcanti (2016), Burnard et al. (2017), and Castillo-Vergara et al. (2018).

Phase 3 consisted of data processing and presenting the results in both quantitative (descriptive) and qualitative (content) formats, following the methodology proposed by Castillo-Vergara et al. (2018) and Cobo et al. (2011, 2012, 2018). Descriptive analysis showed the main areas of related research areas, the main authors, publications, journals, and the geographical scope of the scientific productions. For content analysis, the main correlations and thematic evolutions among the themes uncertainty analysis, LCA, and biorefineries were presented using infographics, keyword co-occurrence networks, strategic diagrams and analysis, and discussion of the most-cited publications for the three main themes identified in each time frame assessed in the present study. 


\section{Results and Discussion}

\section{Descriptive Analysis}

Figure 1 depicts the 10 main areas of research identified, with engineering representing 37 studies (58\%) of the total of 64 publications in the basis of reference. The studies in this area focused on chemical and biochemical engineering, especially because of the relevance of the challenges, issues, and uncertainties related to the biomass supply chain for energy conversion, biofuels, and value-added coproducts. The figure shows that the total number of documents was higher than that of publications; i.e., the same publication could be related to more than one field of research.

Table 2 lists the five main authors with the most published studies, classified according to their respective impact factors (h-index or HI). The first two authors were Fengqi You from Cornell University, with studies about biofuel and bioenergy supply chain modeling and optimization, and Gürkan Sin from the Technical University of Denmark, with studies about uncertainty analysis and risk management in environmental sustainability processes. Considering a total of the 17 publications listed in the table, most authors were affiliated with institutions in the USA, accounting for 53\% of the scientific production.

Table 3 presents the five most-cited publications. The top two were by Cherubini et al. (2009) and addressed issues regarding LCA studies for biofuel and bioenergy and relevant recommendations, while You et al. (2012) investigated models for optimizing biofuel supply chains.

Figure 2 presents the top ten journals, their respective numbers of publication, and impact factors. These journals included $51.5 \%$ of the total number of publications, and the Journal of Cleaner Production headed the list with six publications in the research area and an impact factor of 5.651 .
Figure 3 shows the ten countries with the highest number of publications. The USA and Denmark accounted for $44 \%$ and $12.5 \%$, respectively, while Brazil represented $6.3 \%$ of the total. The countries identified on the map in descending order of publications are USA (28), Denmark (8), Brazil, China and Portugal (4 each), and Austria, Holland, France, Spain, and Belgium (3 each).

\section{Content Analysis}

Figure 4 presents an infographic with the main keywords extracted by VOSviewer. The top five terms were $L C A$ (37), biofuels (31), energy (21), and biomass and biorefinery (18 each), while uncertainty and uncertainty analysis resulted in 13 and 5 occurrences, respectively. It is worth noting that the low occurrence of a keyword does not imply irrelevance or lack of correlation with the other main keywords.

Figure 5 illustrates the correlations among the main keywords using a co-occurrence network, in which the thickness of the lines indicates the strength of the correlations between the nodes (keywords), calculated by counting the number of publications in which the two keywords occur together. The size of the nodule reveals its weight (representativeness) in the network, which is determined by the total number of occurrences of the node. The network clearly shows a connection among the three keywords investigated in this study (uncertainty analysis, LCA, and biorefinery) through the strength of correlations among the keywords LCA, biofuels, energy, biomass, and biorefinery and, at a lower level, between the keywords uncertainty analysis and LCA, uncertainty and $L C A$, and biofuels and biorefinery. Van Eck and Waltman (2018) established the following rules for adequately interpreting a co-occurrence network: (1) the closer to yellow and green the node, the higher its relevance in the network; (2) the numeric scale presented in the lower right corner of the figure presents the average number of citations of publications

Fig. 1 Ten main fields of research

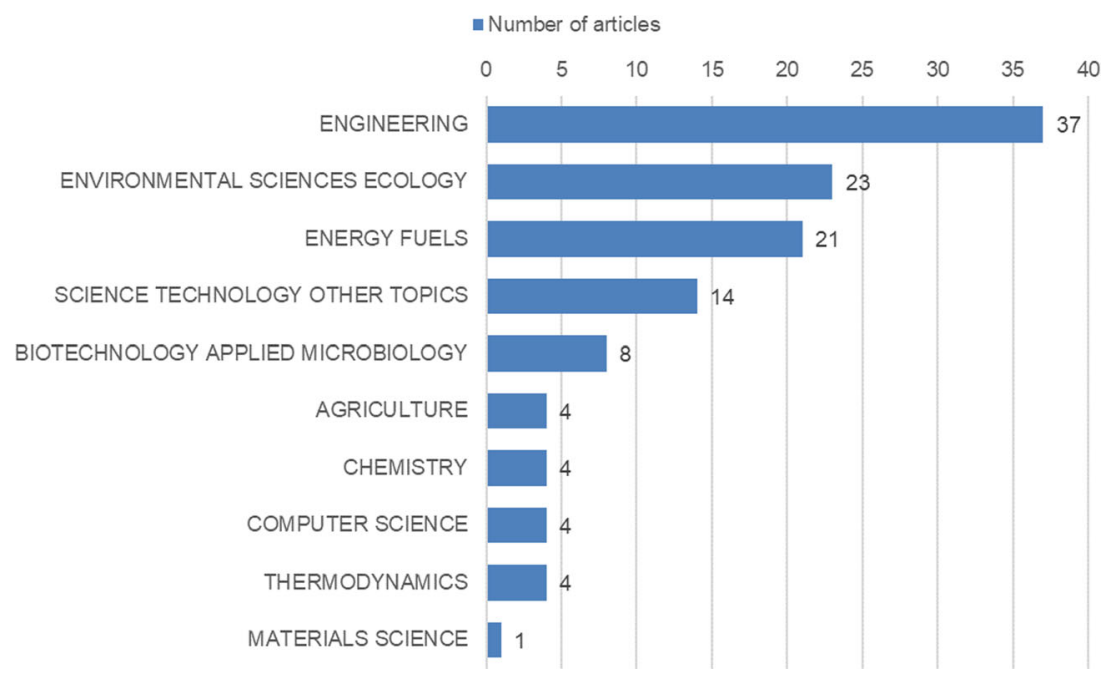


Table 2 The five authors with the highest number of publications (NP), HI, affiliations, and country of affiliation. Source of HI: Scopus ${ }^{\circledR}$

\begin{tabular}{lllll}
\hline Author & NP & HI & Affiliation & Country \\
\hline You, Fengqi & 6 & 44 & Cornell University & USA \\
Sin, Gurkan & 3 & 30 & Danmarks Tekniske Universitet & Denmark \\
Cherubini, Francesco & 3 & 29 & Norges Teknisk-Naturvitenskapelige Universitet & Norway \\
Jungmeier, Gerfried & 2 & 15 & Joanneum Research Forschungsgesellschaft mbH & Austria \\
Gong, Jian & 3 & 13 & Cornell University & USA \\
\hline
\end{tabular}

in which the node occurs; e.g., the mean number of citations of the publications in which uncertainty, LCA, and biorefinery occurred was between 40 and 60 citations, while the keyword uncertainty analysis presented a mean of 20 citations.

To visualize the thematic evolution of the main keywords, Fig. 6 presents a strategic diagram for each time period. A strategic diagram is a bidimensional graphic representation that shows the thematic nuclei (most representative keywords) arranged in four groups and measured according to two standards: centrality (level of interaction) and density (weight). The greater the centrality and density, the more relevant the thematic nucleus in the context of the study. The groups are represented by the following quadrants: (1) motor themes (upper right quadrant), which are well-developed themes that are important to structuring a field of research; (2) basic and transversal themes (lower right quadrant), which are important to a field of research but not sufficiently developed; (3) themes that are emergent or decadent (lower left quadrant); (4) peripheral and isolated themes (upper left quadrant); or (5) themes that are internally well-developed but isolated from other themes and are of marginal importance to developing the field of research.

The study of Cobo et al. (2018) established that (1) the main thematic nuclei are formed by well-defined motor and basic themes and that (2) the diameter of the sphere is proportional to the number of publications that cite each thematic nucleus.

Figure 6 shows that in 2008-2014, three main thematic nuclei stood out, and of these, biofuels and biorefinery were clearly identified as motor themes, while biomass emerged as a basic theme. In 2015-2018, three main thematic nuclei also emerged, in which the LCA was a motor theme, and biofuels and biomass remained as motor and basic themes, respectively. In both periods, the term supply chain evolved as a motor theme (high density and moderate centrality), defined mainly by analysis in scenarios uncertainty (Nguyen et al. 2014; Osmani and Zhang 2014; Tong et al. 2014); impact assessments involving environmental, social, and economic aspects (Bakshi 2014); and supply chain optimization studies and also scenarios uncertainty, especially in terms of the pathways for biofuel and energy production inputs (Malça and Freire 2010; Awudu and Zhang 2012; You et al. 2012; Gong and You 2014).

The term biorefinery, which was considered a motor theme in 2008-2014, turned to be a peripheral theme in 2015-2018. It may suggest that the research related to the topic shifted from a concept development scenario to a more consolidated theme, especially because of emerging practical applications and its undisputed relevance in studies related to bioeconomy, especially in Europe, as can be seen in the European plan of action for the circular economy (European Commision 2015). Considering this consolidation of the term biorefinery, the term $L C A$ evolved as a motor theme in 2015-2018. One factor that explains this thematic evolution is the advent of the circular economy for the business world in mid-2014, indicating that sustainability and environmental impact reduction as strategic requirements for the life cycle perspective in each step of the value chain in the process production of products and services - e.g., feedstocks supply chain, transportation logistics, and waste management (Ellen MacArthur Foundation 2014; European Commision 2015; CNI 2018; Saavedra et al. 2018).

The themes uncertainty analysis and uncertainty were not identified as the main thematic nuclei in any of the analyzed periods. Together with the low occurrence of these themes (Figs. 4 and 5), this demonstrates that although it is an important issue, uncertainty analysis in LCA is a secondary study and has not been cited as frequently in the keywords of
Table 3 The five most cited publications, journals, and total number of citations

\begin{tabular}{lll}
\hline Reference & Journal & Citations \\
\hline Cherubini et al. (2009) & Resources Conservation and Recycling & 427 \\
You et al. (2012) & Aiche Journal & 293 \\
Cherubini and Ulgiati (2010) & Applied Energy & 245 \\
Yue et al. (2014) & Computers \& Chemical Engineering & 203 \\
Cherubini and Jungmeier (2010) & International Journal of Life Cycle Assessment & 130 \\
\hline
\end{tabular}


Fig. 2 Top ten journals

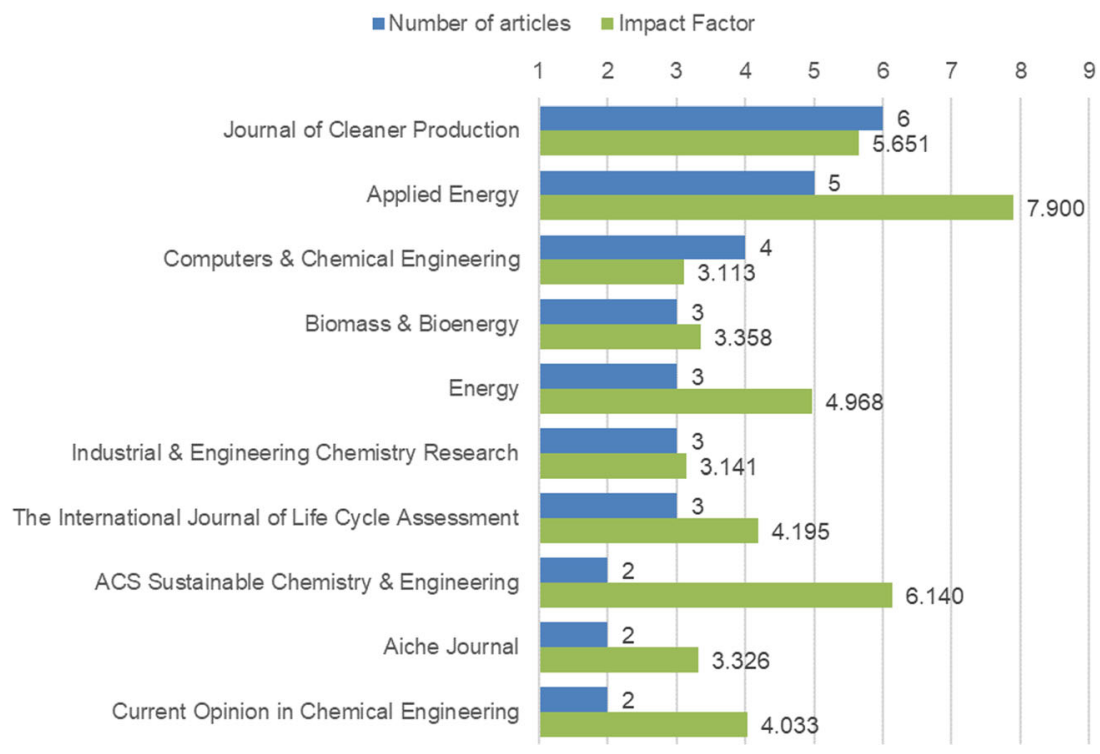

publications, or is not commonly conducted in practice, and when it is, it still represents a lower percentage of studies (Gargalo et al. 2016).

The theme technoeconomic analysis saw a decline between the analyzed periods, in addition to low occurrence (Figs. 4 and 5). However, it is necessarily addressed in studies that discuss, among other things, economic performance in the production of products derived from renewable resources (Paap et al. 2013; Pourhashem et al. 2013).
Tables 4 and 5 present the performance of each of the main thematic nuclei $(\mathrm{TN})$, considering the following measurements: number of publications (NP), citations (CT), h-index (HI), centrality, and density. For each TN, the five most cited publications were included based on the bibliometric analysis results of the SciMAT tool. The data are arranged by level of density. The three themes with the best performance in 2008 2014 were biofuels, biorefinery and biomass, while LCA, biofuels, and biomass stood out in 2015-2018.

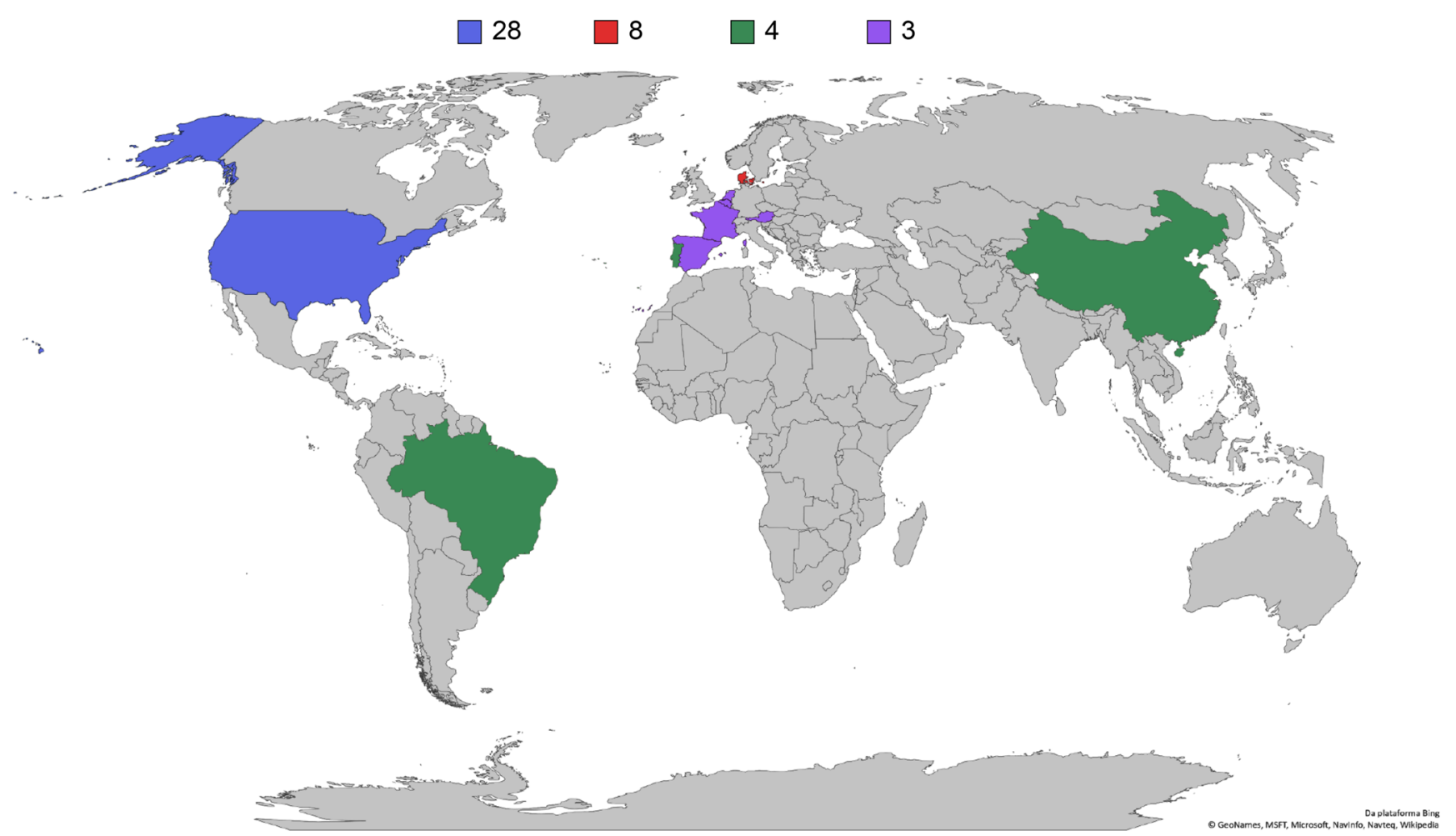

Fig. 3 Top ten countries with the most publications 
Fig. 4. Infographic of main keywords. Source: adapted from Wordle (Feinberg 2014)

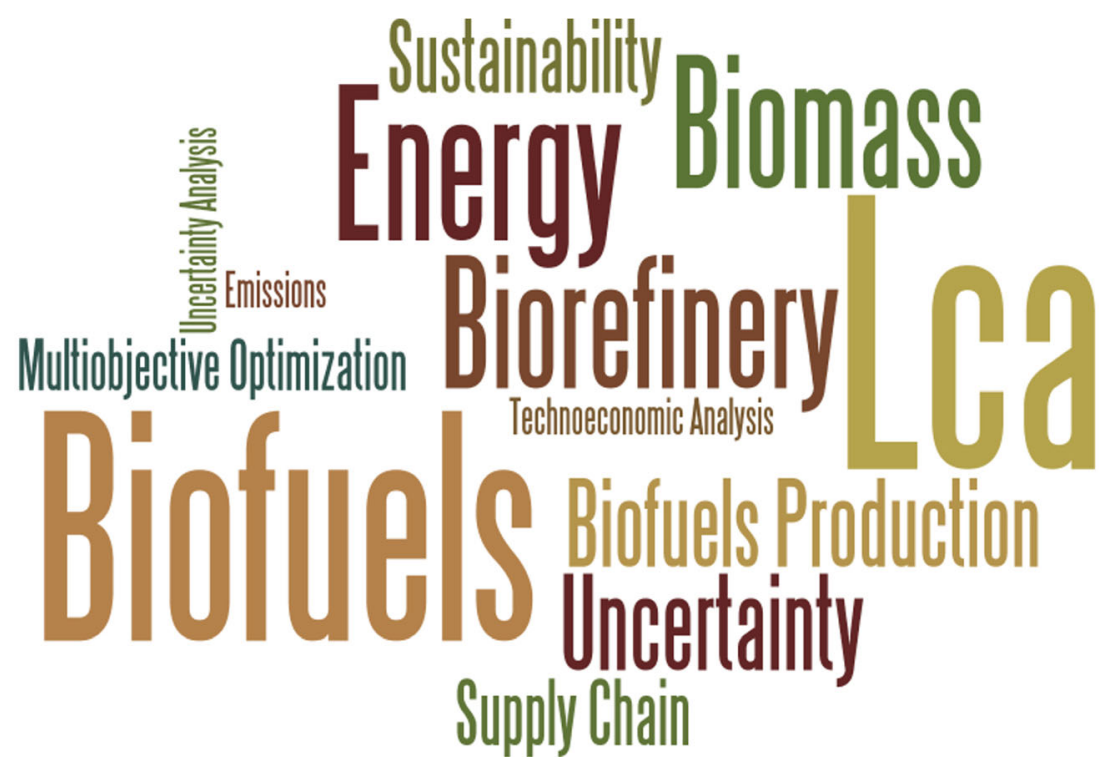

Twenty publications are cited in Tables 4 and 5. Seven of them $(35 \%)$ addressed uncertainties analysis aiming to increase the reliability of data obtained with LCA, as emphasized on Baker and Lepech (2009), and some of the studies also cited some uncertainties related sources and specific methods. The highlights for these publications are presented as follow: Cherubini et al. (2009) pointed out the difficulty of completely avoiding uncertainty when applying LCA to bioenergetic systems, because some of the parameters relevant to these systems are not well known, such as nitrous oxide emissions and changes in soil carbon reservoirs; You et al.
(2012) suggested further studies to investigate other issues, as uncertainties related to fluctuations in the demand for ethanol, interruptions in biomass supply, emergence of more efficient conversion technologies, and changes in government incentives, among others, that are involved in biofuel supply chains, in order to solidly create and operate these chains; Yue et al. (2014) emphasized the relevance of LCA in assessing the environmental impacts on these chains and highlighted the importance of uncertainty analysis to ensure the reliability of LCA results. In addition to the correlation between sources and types of uncertainty, usually found within the scope of
Fig. 5 Co-occurrence network for main keywords. Source: Adapted from VOSviewer

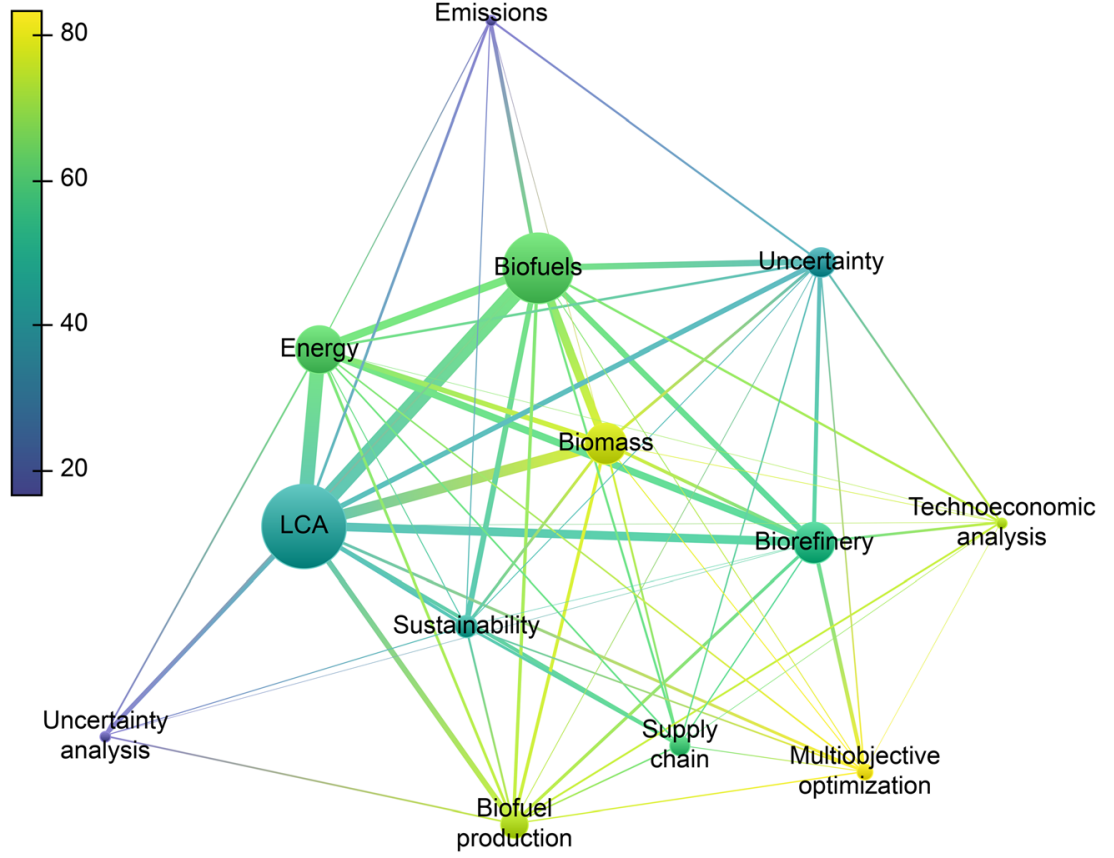

VOSviewer 
a

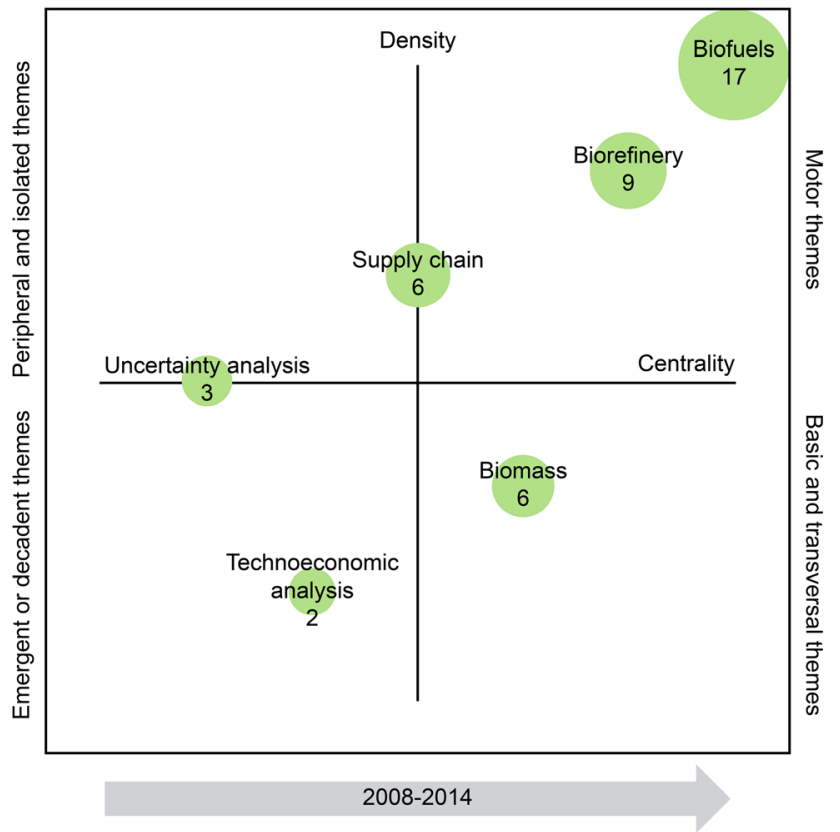

b

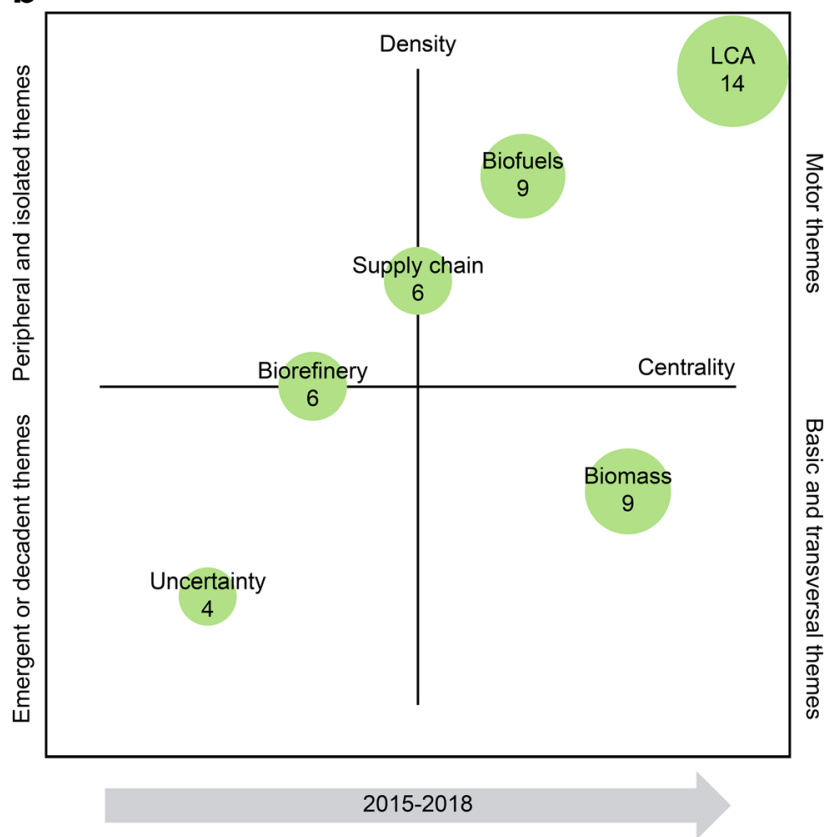

Fig. 6 Strategic diagrams: (a) 2008-2014; (b) 2015-2018. Source: Adapted from SciMAT

biofuel and bioenergy supply chains, the authors also suggested potential approaches for uncertainties analysis, including scenario analysis, stochastic programming, robust optimization, and fuzzy methods; Čuček et al.(2014) present a multiperiod synthesis and optimization model for integrated biorefinery systems (biofuels) and suggested that this model can improve the uncertainties analysis for these biorefineries; Carneiro et al. (2017) emphasized the relevance of addressing potential uncertainties in the algae biomass supply chain, which stem from various production pathways analyzed, especially when it comes to producing third-generation biofuels, because of this technology's stage of development and the many existing pathway options; Cong et al. (2017) addressed the need to discuss uncertainties related to the option of $\mathrm{CH}_{4}$ (methane) compared to diesel in the transport sector's and the some examples of types of uncertainty that should be discussed relates to vehicles cost and storage infrastructure in the $\mathrm{CH}_{4}$ supply chain; and Maes et al. (2015) concluded that when there are uncertainties about the labeling of residue that is added to the process, the results do not reflect a wideranging view of the production chain, and they integrate low impacts regarding toxic emissions and reduce the precision of the allocation of these impacts to the products and coproducts generated. The opposite is true when inflows are labeled clearly as value-added residue. This shows the need to be careful and precise when dealing with different sources and types of uncertainty in material supply pathways, as well as the input parameters of impact assessments.

Table 6 presents the other 13 studies $(65 \%)$, directly related to challenges and approaches for uncertainties analysis in LCA, applied to biorefineries systems and/or their components (e.g., supply chain, economic analysis, environment impact), considering the following characteristics: reference (RF), type of publication (TP), strategy adopted (ST), the approach (AP), and tool used. The main aspects about uncertainties discussions are presented as follow.

\section{From 2008 to 2014}

Cherubini and Ulgiati (2010) presented an investigation applying sensitivity analysis for various input parameters and resulting greenhouse gas emissions, measuring the effects of land use changes and corn stover crop residue removal and its use as a raw material in biorefineries. The authors approached this technique with the explicit goal of reviewing the results of the analysis, identifying the parameters ("key parameters") that most influenced the results, and verifying the precision of the data. They concluded that for the case of the LCA study presented in the publication, the most uncertain parameter was the factor used to estimate the amount of carbon reservoir reduction as a result of corn stover removal. This reduction turns to be the key parameter, which strongly affects the final balance of greenhouse gas emissions for a biorefinery system. Cherubini and Jungmeier (2010) applied a sensitivity analysis with same goal addressed by Cherubini and Ulgiati (2010), i.e., review the results, identifying the parameters that most influence the results (change in soil $\mathrm{C}$ pools and $\mathrm{N}_{2} \mathrm{O}$ soil emissions), and check the data accuracy. Both studies applied LCA to biorefinery case studies. Floudas et al. (2012) analyze 
Table 4 Performance of main thematic nuclei: 2008-2014

\begin{tabular}{|c|c|c|c|c|c|}
\hline $\mathrm{TN}$ & NP & CT & HI & Centrality & Density \\
\hline Biofuels & 17 & 1600 & 12 & 51.02 & 34.40 \\
\hline \multicolumn{6}{|c|}{ Cherubini et al. (2009); You et al.(2012); Cherubini and Ulgiati (2010); Yue et al. (2014); Cherubini and Jungmeier (2010) } \\
\hline Biorefinary & 9 & 784 & 8 & 43.54 & 25.96 \\
\hline \multicolumn{6}{|c|}{ Cherubini and Ulgiati (2010); Yue et al. (2014); Cherubini and Jungmeier (2010); Floudas et al. (Floudas et al. 2012); Čuček et al. (2014 } \\
\hline Biomass & 6 & 735 & 6 & 43.43 & 14.29 \\
\hline
\end{tabular}

optimization thermochemical process to fuel production from three feedstocks (coal, natural gas, and biomass). The authors present a review about important approaches for these feedstock supply chains, among them are LCA, sensitivity/ uncertainty analysis, and related approaches such as MC, MILP, MINLP, and FP. They also indicate that uncertainty is a "challenge and opportunity" component to be addressed in energy balance processes for feedstock supply chains. Osmani and Zhang (2014) present a review of uncertainty scenarios such as: biomass supply chain, bioethanol (lignocellulosic fuel) demand, feedstock purchase price, and bioenergy product sale price. This research focuses on the financial and environmental performance of the bioethanol feedstock supply chain, in particular, to minimize $\mathrm{C}$ emissions. The study also emphasizes that uncertainty scenarios are best evaluated by stochastic methods (e.g., MC) than deterministic methods (e.g., linear optimization models as MILP and MINLP) and presents the results comparing these two approaches and presents a hybrid model (two-stage SMILP). Likewise Cherubini and Ulgiati (2010) and Cherubini and Jungmeier (2010), the authors also applied a sensitivity analysis to verify the influence of uncertainty parameters. Nguyen et al. (2014) focused on the supply chain of the lignocellulosic fuel production, identifying corn stover as the main feedstock at Kansas, USA. The use of MC approach was discussed, by applying Oracle Crystal Ball® tool (Oracle Corporation 2017) for the sensitivity and uncertainty analysis of various uncertainty scenarios around this supply chain on biorefinery systems. In the same way of the previous study, Paap et al. (2013) detailed the strategy to identify the influence of some parameters related to the pretreatment, hydrolysis, and fermentation steps, in the evaluation of uncertain scenarios for a technology under development and commercial scale unproven. The authors evaluated the production process of products derived from switchgrass feedstock and analyzed the influence of these parameters on the production process by using a MC approach in the Crystal Ball® add-in for Microsoft Excel® tool.

\section{From 2015 to 2018}

Souza et al. (2015) presented an interesting case study involving an integrated biorefinery system. The study compared the impact assessment results for the traditional ethanol production system, the production of algal biomass-derived biodiesel, and the proposed biorefinery system. Due to the specificities of each system, which could cause inconsistencies in the results, sensitivity and uncertainty analysis was conducted for the input parameters using the traditional MC approach in the Oracle Crystal Ball®. The authors emphasized that the analysis were based on projected performance, which indicates the presence of high levels of uncertainty and must be potentially treated. Farzad et al. (2017) presented a sensitivity analysis related to price parameters aiming to demonstrate the economic viability of installing a biorefinery to produce lignocellulosic sugarcane biofuel. The approach applied for the sensitivity analysis was MC, and the LCA was performed with SimaPro. Boldrin and Astrup (2015) discussed how the uncertainty analysis can be applied to distinct sustainability policies (e.g., European Union Renewable Energy Directive - RED and United States Renewable Fuel Standard - RFS) with

Table 5 Performance of main thematic nuclei: 2015-2018

\begin{tabular}{|c|c|c|c|c|c|}
\hline $\mathrm{TN}$ & NP & $\mathrm{CT}$ & HI & Centrality & Density \\
\hline$L C A$ & 14 & 90 & 6 & 47.73 & 22.58 \\
\hline \multicolumn{6}{|c|}{ Carneiro et al. (2017); Souza et al. (2015); Cong et al. (2017); Farzad et al. (Farzad et al. 2017); Boldrin and Astrup (2015) } \\
\hline Biofuels & 9 & 43 & 3 & 37.92 & 17.02 \\
\hline \multicolumn{6}{|c|}{ Souza et al. (2015); Farzad et al. (Farzad et al. 2017); Agostinho et al. (2015); Bairamzadeh et al. (2018); Pérez-López et al. (2018) } \\
\hline Biomass & 9 & 111 & 7 & 44.67 & 14.21 \\
\hline
\end{tabular}


Table 6 The main references directly related to uncertainties approaches

\begin{tabular}{lllll}
\hline RF & TP & ST & AP & Tool \\
\hline 2008-2014 & & & & \\
Cherubini and Ulgiati (2010) & CS & SA & NI & SimaPro 7.1 \\
Cherubini and Jungmeier (2010) & CS & SA & NI & SimaPro 7 \\
Floudas et al. (2012) & RW & SA, UA & MC, MILP, MINLP, FP & NI \\
Osmani and Zhang (2014) & CS & SA, UA & NI/2-Stage SMILP & NI \\
Nguyen et al. (2014) & CS & UA & MC & Oracle Crystal Ball@ \\
Paap et al. (2013) & CS & SA & MC & Crystal Ball@ add-in for Microsoft Excel® \\
2015-2018 & & & & \\
Souza et al. (2015) & CS & SA, UA & MC & Oracle Crystal Ball@ \\
Farzad et al. (2017) & CS & SA & MC & SimaPro 3.2 \\
Boldrin and Astrup (2015) & CS & UA & MC & SimaPro 7.3.3 \\
Agostinho et al. (2015) & CS & SA, UA & MC & MC-Simulation add-in for Microsoft Excel@ \\
Bairamzadeh et al. (2018) & CS, RW & UA & MILP & NI \\
Pérez-López et al. (2018) & CS & SA, UA & MC & @ RISK add-in for Microsoft Excel® \\
Gong and You (2017) & CS & UA & 2-Stage ARMIFP & NI
\end{tabular}

CS, case study; RW, review; SA, sensitivity analysis; UA, uncertainty analysis; MC, Monte Carlo; MILP, mixed integer linear program; MINLP, mixed integer nonlinear optimization; SMILP, stochastic milp; ARMIFP, adaptive model to mixed integer fractional programming; FP, fuzzy programming; NI, uninformed

MC approach and SimaPro tool applied to assess uncertain scenarios around the production system of biofuels on biorefineries. Agostinho et al. (2015) adopted an uncertainty analysis with a MC approach through the MC-Simulation Add-In for Microsoft Excel® tool developed by Barreto and Howland (2010). Like the previous studies, the authors performed an uncertainty analysis to assess potential uncertainties in input parameters related to cellulase enzyme industrial production, in this case. In the same way of Osmani and Zhang (2014), the authors briefly discussed the differences between stochastic and deterministic models, to evaluate uncertainty scenarios in LCA studies. Bairamzadeh et al. (2018) presented a robust MILP approach to verify sources and types of uncertainty on lignocellulosic biofuel (bioethanol) supply chain. The authors identified the main sources, types, and uncertainties approaches that can applied in this supply chain through a literature review. Pérez-López et al. (2018) also addressed an analysis around uncertainties parameters related to economic and environmental assessment on a biorefinery system in the same way of You et al.(2012), Yue et al. (2014), Cong et al. (2017), and Farzad et al. (2017). In this study the authors evaluate a microalgal biorefinery to produce renewable fuel and coproducts. Considering that the discussion addressed technologies under development, there were potential uncertainties scenarios to be analyzed. The authors investigated the influence of these uncertainties applying sensitivity and uncertainty analysis, using a MC approach through the @ RISK add-in for Microsoft Excel® tool. Gong and You (2017) presented a processing network with over 46,000 alternative production pathways for fuels and value- added products based on algae biomass, indicating a robust mathematical model to support decisions about obtaining fuels and microalgae-based bioproducts with a maximum return on investment (ROI). For a study with this scope, an elevated level of uncertainty in the model's input parameters is to be expected. To process these uncertainties, the authors developed a deterministic model, 2-Stage ARMIFP, in order to identify, within the network and based on the indicated parameters, the optimal pathway that yields the highest ROI. An optimal processing pathway was proposed with the following characteristics: open pond, polyelectrolyte-based flocculation, filtration, high-pressure homogenization, supercritical $\mathrm{CO} 2$ extraction, and transesterification catalyzed with sodium methoxide, among others. The model also indicated that the highest productivity would be $25.94 \%$. For future studies, the authors indicated the need for species of microalgae with higher oil productivity and high biomass concentration.

\section{Final Considerations}

The present study, which utilized a systematic and bibliometric approach to a literature review, resulted in a broad scientific mapping of how the theme uncertainty analysis is discussed, together with $L C A$ and biorefinery. The results clearly indicate that in the last 10 years, uncertainty analysis has been treated primarily as a way to help validate the results of LCA studies, when it is applied in scenarios that involve multiple sources and different types of uncertainties, as is the case for biorefinery systems. A total of 64 scientific publications came from the WoS and Scopus ${ }^{\circledR}$ 
databases, and $72.7 \%$ of the publications from Scopus ${ }^{\circledR}$ were also listed in the WoS. Thus, the WoS was considered the basis of reference for the computational analysis. The publications included research carried out in the last 10 years and were divided into two time periods: 2008-2014 and 2015-2018.

The results were presented both in quantitative (descriptive) and qualitative (content) formats. Regarding the descriptive results, the studies were mostly concentrated in the fields of chemical and biochemical engineering. The journal with the highest number of publications was the Journal of Cleaner Production, edited by Elsevier, which addresses research and practices in sustainability, environment, and cleaner production. In geographical terms, as observed for the authors with the greatest impact factors and most-cited publications, most studies were from the USA, with $44 \%$, followed by Europe, with $42 \%$, while Brazil accounted for $6.3 \%$ of the scientific production found in the present study.

Regarding content analysis, the correlations and evolution of the studied themes were investigated through infographics, co-occurrence networks, and strategic keyword diagrams. Graphic analysis showed that in 2008-2014, the theme biorefinery stood out, a concept that gained greater consolidation as a motor theme in the context of bioeconomy. In 20152018, the motor theme was LCA, which was strongly correlated to studies about bioenergy, with relevant discussions about the sustainability and viability of fuel and energy production pathways through renewable resources. This study revealed low occurrence of uncertainty analysis in both periods. This low occurrence does not indicate the theme's irrelevance, but only that the studied publications treated uncertainties as a secondary subject, serving to support the validation of results. The results displayed in the graphic analysis were explored by analyzing and discussing the most-cited publications that were related to the main thematic nuclei of each period. The strategy used in this study contributed to a detailed understanding and scientific mapping of various issues and challenges when handling uncertainties in order to minimize risks and errors in environmental impact assessment diagnoses using the LCA technique. It can also help identify the various sources and types of uncertainty, as well as possible approaches to LCA, such as statistical and probabilistic models, and fuzzy methods, among others.

Future studies in the area should include in-depth investigations for the use of advanced probabilistic techniques, such as probabilistic ontologies, to add value to investigations of knowledge representation and reasoning about uncertainties in all stages of LCA studies, especially in the context of complex environments such as biorefinery systems. There are still few guidelines provided in the literature in the area of study of probabilistic ontologies. However, details and discussions in this field of research and yours evolutions have been addressed by Carvalho et al. (2011, 2013, 2016, 2017) and Riali et al. (2019).
Acknowledgments The authors thank for the financial support from the Innovation and Research Funding, FINEP, through the NEXTBIO project (grant number 0677/16). We also express our appreciation for the reviewers and discussions promoted by our peers in the Crosscutting Studies Group at Embrapa Agroenergy. They helped us understand and investigate the details and complexities involved in impact assessment studies, especially Rosana do Carmo Nascimento Guiducci and Priscila Seixas Sabaini.

\section{Compliance with Ethical Standards}

Conflict of Interests On behalf of all authors, the corresponding author states that there is no conflict of interest.

Open Access This article is licensed under a Creative Commons Attribution 4.0 International License, which permits use, sharing, adaptation, distribution and reproduction in any medium or format, as long as you give appropriate credit to the original author(s) and the source, provide a link to the Creative Commons licence, and indicate if changes were made. The images or other third party material in this article are included in the article's Creative Commons licence, unless indicated otherwise in a credit line to the material. If material is not included in the article's Creative Commons licence and your intended use is not permitted by statutory regulation or exceeds the permitted use, you will need to obtain permission directly from the copyright holder. To view a copy of this licence, visit http://creativecommons.org/licenses/by/4.0/.

\section{References}

Agostinho F, Bertaglia ABB, Almeida CMVB, Giannetti BF (2015) Influence of cellulase enzyme production on the energeticenvironmental performance of lignocellulosic ethanol. Ecol Model 315:46-56. https://doi.org/10.1016/j.ecolmodel.2014.09.005

Awudu I, Zhang J (2012) Uncertainties and sustainability concepts in biofuel supply chain management: a review. Renew Sust Energ Rev 16:1359-1368. https://doi.org/10.1016/j.rser.2011.10.016

Bairamzadeh S, Saidi-Mehrabad M, Pishvaee MS (2018) Modelling different types of uncertainty in biofuel supply network design and planning: a robust optimization approach. Renew Energy 116: 500-517. https://doi.org/10.1016/j.renene.2017.09.020

Baker JW, Lepech MD (2009) Treatment of uncertainties in life cycle assessment. In: 10th international conference on structural safety and reliability, Osaka, Japan

Bakshi BR (2014) Methods and tools for sustainable process design. Curr Opin Chem Eng 6:69-74. https://doi.org/10.1016/j.coche.2014.09.005

Barreto H, Howland FM (2010) Introductory Econometrics. http:// www3.wabash.edu/econometrics/index.htm. Accessed 30 Oct 2019

Boldrin A, Astrup T (2015) GHG sustainability compliance of rapeseedbased biofuels produced in a Danish multi-output biorefinery system. Biomass Bioenergy 75:83-93. https://doi.org/10.1016/j. biombioe.2015.01.023

Burnard M, Posavčević M, Kegel E (2017) Examining the evolution and convergence of wood modification and environmental impact assessment in research. iForest Biogeosci For 10:879-885. https:// doi.org/10.3832/ifor2390-010

Carneiro MLNM, Pradelle F, Braga SL et al (2017) Potential of biofuels from algae: comparison with fossil fuels, ethanol and biodiesel in Europe and Brazil through life cycle assessment (LCA). Renew Sust Energ Rev 73:632-653. https://doi.org/10.1016/j.rser.2017.01.152

Carvalho RN, Haberlin R, da Costa PCG, et al (2011) Modeling a probabilistic ontology for Maritime Domain Awareness. In: Proceedings of the 
14th International Conference on Information Fusion, \{FUSION\} 2011, Chicago, Illinois, USA, July 5-8, 2011. IEEE, pp 1-8

Carvalho RN, Matsumoto S, Laskey KB, et al (2013) Probabilistic ontology and knowledge Fusion for procurement fraud detection in Brazil. In: Uncertainty Reasoning for the Semantic Web II. pp 19-40

Carvalho RN, Laskey KB, Da Costa PCG (2016) Uncertainty modeling process for semantic technology. PeerJ Comput Sci 2:e77. https:// doi.org/10.7717/peerj-cs.77

Carvalho RN, Laskey KB, Costa PCG (2017) PR-OWL - a language for defining probabilistic ontologies. Int J Approx Reason 91:56-79. https://doi.org/10.1016/j.ijar.2017.08.011

Castillo-Vergara M, Alvarez-Marin A, Placencio-Hidalgo D (2018) A bibliometric analysis of creativity in the field of business economics. J Bus Res 85:1-9. https://doi.org/10.1016/j.jbusres.2017.12.011

Cavalcanti PdeS (2016) Sistemas de Medição de Desempenho : Revisão Sistemática da Literatura e Análise Bibliométrica. PUC-RIO

Cherubini F, Jungmeier G (2010) LCA of a biorefinery concept producing bioethanol, bioenergy, and chemicals from switchgrass. Int J Life Cycle Assess 15:53-66. https://doi.org/10.1007/s11367-009-0124-2

Cherubini F, Ulgiati S (2010) Crop residues as raw materials for biorefinery systems - a LCA case study. Appl Energy 87:47-57. https://doi.org/10.1016/j.apenergy.2009.08.024

Cherubini F, Bird ND, Cowie A et al (2009) Energy- and greenhouse gasbased LCA of biofuel and bioenergy systems: key issues, ranges and recommendations. Resour Conserv Recycl 53:434 447. https://doi. org/10.1016/j.resconrec.2009.03.013

CNI (2018) Circular economy: opportunities and challenges for the brazilian industry. National Confederation of Industry (CNI), Brasília

Cobo MJ, López-Herrera AG, Herrera-Viedma E, Herrera F (2011) An approach for detecting, quantifying, and visualizing the evolution of a research field: a practical application to the fuzzy sets theory field. J Inf Secur 5:146-166. https://doi.org/10.1016/j.joi.2010.10.002

Cobo MJ, López-Herrera AG, Herrera-Viedma E, Herrera F (2012) SciMAT: a new science mapping analysis software tool. J Am Soc Inf Sci Technol 63:1609-1630. https://doi.org/10.1002/asi.22688

Cobo MJ, Pérez IJ, Cabrerizo FJ, et al (2018) Co-words analysis of the last ten years of the fuzzy decision making research area. In: Advances in Intelligent Systems and Computing. pp 497-508

Cong RG, Termansen M (2016) A bio-economic analysis of a sustainable agricultural transition using green biorefinery. Sci Total Environ 571:153-163. https://doi.org/10.1016/j.scitotenv.2016.07.137

Cong R-G, Caro D, Thomsen M (2017) Is it beneficial to use biogas in the Danish transport sector? - an environmental-economic analysis. J Clean Prod 165:1025-1035. https://doi.org/10.1016/j.jclepro.2017.07.183

Cronin P, Ryan F, Coughlan M (2008) Undertaking a literature review: a step-by-step approach. Br J Nurs 17:38-43

Čuček L, Martín M, Grossmann IE, Kravanja Z (2014) Multi-period synthesis of optimally integrated biomass and bioenergy supply network. Comput Chem Eng 66:57-70. https://doi.org/10.1016/j. compchemeng.2014.02.020

Curran MA (2012) Life cycle assessment handbook

den Hollander MC, Bakker CA, Hultink EJ (2017) Product Design in a Circular Economy: development of a typology of key concepts and terms. J Ind Ecol 21:517-525. https://doi.org/10.1111/jiec.12610

Ellen MacArthur Foundation (2014) Towards the circular economy: accelerating the scale-up across global supply chains. Geneva, Switzerland

Embrapa (2018) Visão 2030 - o futuro da agricultura brasileira. Brasília, Brazil

European Commision (2015) An EU action plan for the circular economy

Farzad S, Mandegari MA, Görgens JF (2017) Integrated technoeconomic and environmental analysis of butadiene production from biomass. Bioresour Technol 239:37-48. https://doi.org/10.1016/j. biortech.2017.04.130

Feinberg J (2014) Wordle. http://www.wordle.net/. Accessed 5 Nov 2019
Finnveden G, Hauschild MZ, Ekvall T, Guinée J, Heijungs R, Hellweg S, Koehler A, Pennington D, Suh S (2009) Recent developments in life cycle assessment. J Environ Manag 91:1-21. https://doi.org/10. 1016/j.jenvman.2009.06.018

Floudas CA, Elia JA, Baliban RC (2012) Hybrid and single feedstock energy processes for liquid transportation fuels: a critical review. Comput Chem Eng 41:24-51. https://doi.org/10.1016/j. compchemeng.2012.02.008

Frischknecht R, Jungbluth N, Althaus H-J et al (2005) The ecoinvent database: overview and methodological framework (7 pp). Int $\mathbf{J}$ Life Cycle Assess 10:3-9. https://doi.org/10.1065/lca2004.10.181.1

Gargalo CL, Cheali P, Posada JA et al (2016) Assessing the environmental sustainability of early stage design for bioprocesses under uncertainties: an analysis of glycerol bioconversion. J Clean Prod 139: 1245-1260. https://doi.org/10.1016/j.jclepro.2016.08.156

Gong J, You F (2014) Optimal design and synthesis of algal biorefinery processes for biological carbon sequestration and utilization with zero direct greenhouse gas emissions: MINLP model and global optimization algorithm. Ind Eng Chem Res 53:1563-1579. https:// doi.org/10.1021/ie403459m

Gong J, You F (2017) Optimal processing network design under uncertainty for producing fuels and value-added bioproducts from microalgae: two-stage adaptive robust mixed integer fractional programming model and computationally efficient solution algorithm. AICHE J 63:582-600. https://doi.org/10.1002/aic

Guinée JB, Heijungs R, Huppes G, Zamagni A, Masoni P, Buonamici R, Ekvall T, Rydberg T (2011) Life cycle assessment: past, present, and future. Environ Sci Technol 45:90-96. https://doi.org/10.1021/ es101316v

Guo M, Murphy RJ (2012) LCA data quality: sensitivity and uncertainty analysis. Sci Total Environ 435-436:230-243. https://doi.org/10. 1016/j.scitotenv.2012.07.006

Gutiérrez-Salcedo M, Martínez MÁ, Moral-Munoz JA, Herrera-Viedma E, Cobo MJ (2017) Some bibliometric procedures for analyzing and evaluating research fields. Appl Intell 48:1275-1287. https://doi. org/10.1007/s10489-017-1105-y

Hellweg S, Mila i Canals L (2014) Emerging approaches, challenges and opportunities in life cycle assessment. Science (80- ) 344:11091113. https://doi.org/10.1126/science. 1248361

Klöpffer W (2014) Background and future prospects in life cycle assessment. Springer, Dordrecht

Maes D, Van Dael M, Vanheusden B et al (2015) Assessment of the sustainability guidelines of EU renewable energy directive: the case of biorefineries. J Clean Prod 88:61-70. https://doi.org/10.1016/j. jclepro.2014.04.051

Malça J, Freire F (2010) Uncertainty analysis in biofuel systems. J Ind Ecol 14:322-334. https://doi.org/10.1111/j.1530-9290.2010.00227. $\mathrm{x}$

Marques T, Reis N, Gomes JFS (2018) Responsible leadership research: a Bibliometric review. BAR Brazilian Adm Rev 15:1-25. https://doi. org/10.1590/1807-7692bar2018170112

Mirkouei A, Haapala KR, Sessions J, Murthy GS (2017) A mixed biomass-based energy supply chain for enhancing economic and environmental sustainability benefits: a multi-criteria decision making framework. Appl Energy 206:1088-1101. https://doi.org/10. 1016/j.apenergy.2017.09.001

Nguyen L, Cafferty KG, Searcy EM, Spatari S (2014) Uncertainties in life cycle greenhouse gas emissions from advanced biomass feedstock logistics supply chains in Kansas. Energies 7:7125-7146. https:// doi.org/10.3390/en7117125

Oracle Corporation (2017) Oracle Crystal Ball. https://www.oracle.com/ applications/crystalball/.

Osmani A, Zhang J (2014) Economic and environmental optimization of a large scale sustainable dual feedstock lignocellulosic-based bioethanol supply chain in a stochastic environment. Appl Energy 114:572-587. https://doi.org/10.1016/j.apenergy.2013.10.024 
Paap SM, West TH, Manley DK et al (2013) Biochemical production of ethanol and fatty acid ethyl esters from switchgrass: a comparative analysis of environmental and economic performance. Biomass Bioenergy 49:49-62. https://doi.org/10.1016/j.biombioe.2012.11.029

Pérez-López P, Montazeri M, Feijoo G, Moreira MT, Eckelman MJ (2018) Integrating uncertainties to the combined environmental and economic assessment of algal biorefineries: a Monte Carlo approach. Sci Total Environ 626:762-775. https://doi.org/10.1016/j. scitotenv.2017.12.339

Perianes-Rodriguez A, Waltman L, van Eck NJ (2016) Constructing bibliometric networks: a comparison between full and fractional counting. J Inf Secur 10:1178-1195. https://doi.org/10.1016/j.joi. 2016.10.006

Pourhashem G, Adler PR, McAloon AJ, Spatari S (2013) Cost and greenhouse gas emission tradeoffs of alternative uses of lignin for second generation ethanol. Environ Res Lett 8. https://doi.org/10.1088/ $1748-9326 / 8 / 2 / 025021$

Rebitzer G, Ekvall T, Frischknecht R, Hunkeler D, Norris G, Rydberg T, Schmidt WP, Suh S, Weidema BP, Pennington DW (2004) Life cycle assessment part 1: framework, goal and scope definition, inventory analysis, and applications. Environ Int 30:701-720. https:// doi.org/10.1016/j.envint.2003.11.005

Riali I, Fareh M, Bouarfa H (2019) Fuzzy probabilistic ontology approach. Int J Semant Web Inf Syst 15:1-20. https://doi.org/10. 4018/IJSWIS.2019100101

Rosengart A, Vizzi M, Manenti F, Citterio A (2017) Development of an ultrafiltration predictive model to estimate the cost of downstream in biorefineries: effects of epistemic experimental uncertainties. Energy Convers Manag 149:875-884. https://doi.org/10.1016/j. enconman.2017.03.043

Saavedra YMB, Iritani DR, Pavan ALR, Ometto AR (2018) Theoretical contribution of industrial ecology to circular economy. J Clean Prod 170:1514-1522. https://doi.org/10.1016/j.jclepro.2017.09.260

Search Technology (1997) VantagePoint User's Guide. Search Technol

Sills DL, Paramita V, Franke MJ, Johnson MC, Akabas TM, Greene CH, Tester JW (2013) Quantitative uncertainty analysis of life cycle assessment for algal biofuel production. Environ Sci Technol 47:687694. https://doi.org/10.1021/es3029236

Souza SP, Seabra JEA (2014) Integrated production of sugarcane ethanol and soybean biodiesel: environmental and economic implications of fossil diesel displacement. Energy Convers Manag 87:1170-1179. https://doi.org/10.1016/j.enconman.2014.06.015

Souza SP, Gopal AR, Seabra JEA (2015) Life cycle assessment of biofuels from an integrated Brazilian algae-sugarcane biorefinery. Energy:81. https://doi.org/10.1016/j.energy.2014.12.050
Stavropoulos P, Giannoulis C, Papacharalampopoulos A et al (2016) Life cycle analysis: comparison between different methods and optimization challenges. Procedia CIRP 41:626-631. https://doi.org/10. 1016/j.procir.2015.12.048

Tang Z-C, Zhenzhou L, Zhiwen L, Ningcong X (2015) Uncertainty analysis and global sensitivity analysis of techno-economic assessments for biodiesel production. Bioresour Technol 175:502-508. https:// doi.org/10.1016/j.biortech.2014.10.162

Team S (2009) Science of science (Sci2) tool. In: Indiana Univ. SciTech Strateg. https://sci2.cns.iu.edu/. Accessed 18 Feb 2019

Tong K, You F, Rong G (2014) Robust design and operations of hydrocarbon biofuel supply chain integrating with existing petroleum refineries considering unit cost objective. Comput Chem Eng 68:128139. https://doi.org/10.1016/j.compchemeng.2014.05.003

Ubando AT, Felix CB, Chen W-H (2019) Biorefineries in circular bioeconomy: A comprehensive review. Bioresource Technology. https://doi.org/10.1016/j.biortech.2019.122585

van Eck NJ, Waltman L (2014) CitNetExplorer: a new software tool for analyzing and visualizing citation networks. J Informetr 8:802-823. https://doi.org/10.1016/j.joi.2014.07.006

Eck NJ Van, Waltman L (2018) VOSviewer Manual. Univ Leiden 1-51

van Leeuwen T (2006) The application of bibliometric analyses in the evaluation of social science research. Who benefits from it, and why it is still feasible. Scientometrics 66:133-154. https://doi.org/10. 1007/s11192-006-0010-7

Venkata Mohan S, Dahiya S, Amulya K, Katakojwala R, Vanitha TK (2019) Can circular bioeconomy be fueled by waste biorefineries - A closer look. Bioresource Technology Reports 7. https://doi.org/ 10.1016/j.biteb.2019.100277

Wagner CS, Roessner JD, Bobb K et al (2011) Approaches to understanding and measuring interdisciplinary scientific research (IDR): a review of the literature. J Inf Secur 5:14-26. https://doi.org/10.1016/j. joi.2010.06.004

You F, Tao L, Graziano DJ, Snyder SW (2012) Optimal design of sustainable cellulosic biofuel supply chains: multiobjective optimization coupled with life cycle assessment and input-output analysis. AICHE J 58:1157-1180. https://doi.org/10.1002/aic.12637

Yue D, You F, Snyder SW (2014) Biomass-to-bioenergy and biofuel supply chain optimization: overview, key issues and challenges. Comput Chem Eng 66:36-56. https://doi.org/10.1016/j. compchemeng.2013.11.016

Publisher's Note Springer Nature remains neutral with regard to jurisdictional claims in published maps and institutional affiliations. 